\title{
Relationship of Socioeconomic Status with Exacerbation Frequency among Children with Asthma in Malaysia
}

\author{
Aniza Ismail ${ }^{1}$, Nurmawati Ahmad ${ }^{2}$, Saperi Sulong ${ }^{3}$, Rusdi Abd Rahman ${ }^{4}$ \\ ${ }^{1,2,3}$ Department of Community Health, Universiti Kebangsaan Malaysia Medical Centre, Malaysia \\ draniza@gmail.com \\ drnurma@yahoo.com \\ saperi@ppukm.ukm.edu.my \\ ${ }^{4}$ District Health Office, Malaysia \\ drrusdi@yahoo.com
}

\begin{abstract}
Background: Less than $25 \%$ of asthmatic children are well controlled. Little is known about how parental socioeconomic status affects the level of control of their children suffering Asthma. This may contribute to the successfulness of universal coverage. Objective: To determine the relationship of socioeconomic status with exacerbation frequency among children with asthma in Malaysia. Method: A cross-sectional study was carried out among 140 children with asthma aged 7 to 17 years old attending government primary health care clinics in Malaysia from December 2015 to June 2016. The respondents were selected via convenient random sampling. The survey was conducted via a face-to-face interview using a standardized self administered questionnaire. Result: The results showed that majority of the respondent showed mean age of 10.7 years and most were males $(55.0 \%)$ with secondary level of education $(33.6 \%)$. Mean exacerbation of disease was $4.9 \pm 1.9 .60 \%$ respondent's caregiver had background of secondary level with majority $(44.3 \%)$ of their family income ranging between (RM2300 - 5599) per month. There was no association was found between the frequency of asthma exacerbation with level of education among respondent's caregiver $(t=-1.38, p=0.17)$ and with level of family income $(F=0.25, p=0.96)$. Conclusion: The socio demographic factor has no relationship with asthma exacerbation. The findings added to the latest knowledge and information of asthma in Malaysia.
\end{abstract}

Keywords — asthma, children, socioeconomic, government primary clinics

\section{INTRODUCTION}

Asthma is a serious public health problem globally, with an estimated 300 million affected individuals and great variations between countries [1]. The prevalence of asthma is increasing in most countries, especially among children and adolescents [2].

In Malaysia, Asthma was also noted to be among the commonest medical conditions treated in health clinics, giving rise to considerable morbidity and mortality [3]. About $73 \%$ of outpatients that attended primary health care clinics were treated for respiratory symptoms, where asthma was one of the cases that needed to be closely treated [4].

Despite advances in asthma management, acute exacerbation continues to occur and impose considerable morbidity on patients and constitute a major burden on health care resources. Other than genetic contribution, there are several social and environmental factors involved in the cause and exacerbation of childhood Asthma. This was included the socioeconomic status (measured by family income, parental education and parental occupation) of the family itself, have an association of the acute exacerbation of asthma among children [5].

This problem is able to impact the patients, their families, and the community as a whole in terms of lost work and school days, poor quality of life, increased use of expensive emergency services, hospitalizations, and deaths [6]. Reducing SES disparities in health will require policy initiatives addressing the components of SES as well as the pathways by which these affect health.

However, there are still few studies done to examine the association of SES with the exacerbation frequency among childhood asthma. Quality in addition, little is known about the factor associated among asthmatic children that could impact their asthma control.

Hence, by doing this study, we aimed to determine whether the SES factor (family income, parental education level and parental occupation) 
were associated with exacerbation frequency among children with asthma attending to primary health clinics. This could eventually improve the plan of management in children with asthma through conclusive recommendations.

\section{METHODOLOGY}

A cross-sectional survey was conducted in two large urban government primary health care centres located in South Malaysia from December 2015 to June 2016, using a convenient sampling strategy. Both government primary health care centres, equipped with all basic amenities of safe water supply, electricity and proper sanitation, has a population of about 16000 with mainly Malay ethnicity.

All asthmatic children aged 7 to 17 years old who registered at the selected settings for follow-up visits during the study period and fulfilled the inclusion criteria were included. A sample size of 140 samplings was estimated using Fleiss J.L formula to detect a prevalence of children with Asthma. An individual was considered asthmatic when medically certified by a physician. The respondents were selected via convenient random sampling. The inclusion criteria were Malaysian citizens and accompanied by his or her caregiver who consented for participating in this study. The exclusion criteria were asthmatic children aged below 7 years or above 17 years, have concomitant illnesses other than asthma, suspicion of having an alternative cause for recurrent wheezing other than asthma, illiterate or refused to participate.

Information was retrieved from the patients and their caregiver. The survey was conducted via a face-to-face interview using a standardized self administered questionnaire. It included data concerning socio-demographic factors such as sex, age, educational level, paternal educational level, paternal occupation and family income.

The approval for this study had been obtained from the Research Ethics Committee, Medical Faculty Universiti Kebangsaan Malaysia (FF-4252012), Medical Centre as well as the National Medical Research Register, National Institute of Health, Malaysia.

Data was analysed using SPSS (Statistical Package for Social Sciences) version 20 (Chicago,
IL, USA). Descriptive data was presented as frequencies and percentages and continuous variables as means with standard deviation (SD). Differences between normally distributed continuous data were analyzed using the independent t-test and one way ANOVA. All tests were two-tailed with significance defined as the $\mathrm{p}$ value of less than 0.05 .

\section{RESULTS}

All paragraphs must be indented. All paragraphs must be justified, i.e. both left-justified and rightjustified.

\section{A. Socio-Demography Characteristics Of Respondents}

A total of 140 caregivers agreed to their child's participation in the study. Table 1 shows the respondents' socio-demography characteristics. The age of the respondents ranged from 7 to 17 years with the mean age of children at 10.7 years \pm 2.66 . Boys were $77(55.0 \%)$ and girls were 63(45.0\%). Ninety-three $(66.4 \%)$ of the respondents were in primary school and 47 (33.6\%) in secondary school.

TABLE I

SOCIO-DEMOGRAPHY CHARACTERISTICS OF RESPONDENTS $(\mathrm{N}=140)$

\begin{tabular}{|c|c|c|}
\hline Parameter & Frequency (n) & Percentage (\%) \\
\hline Age (years) & \multicolumn{2}{|c|}{ Mean : 10.7 years \pm 2.66} \\
\hline Exacerbation of Asthma & \multicolumn{2}{|c|}{ Mean : $4.9 \pm 1.9$} \\
\hline \multicolumn{3}{|l|}{ Level of Education } \\
\hline Primary & 93 & 66.4 \\
\hline Secondary & 47 & 33.6 \\
\hline \multicolumn{3}{|l|}{ Gender } \\
\hline Male & 77 & 55.0 \\
\hline Female & 63 & 45.0 \\
\hline
\end{tabular}

\section{B. Socio-Demography Characteristics of Respondent's Caregiver}

Table 2 delineates the socio-demography characteristics of the respondents' caregivers. Majority of the respondents' paternal educational levels have primary education level. The technical work was the main paternal occupation $(50.0 \%)$ in the studied sample. Otherwise others included in the professional $931.4 \%$ ) and self employed $(18.6 \%)$. Sixty-two $(44.3 \%)$ of the respondents' caregivers had their family income ranging between (RM2300 - 5599). 
B. Association of Socio-Demography Characteristics of Respondents with Exacerbation of Asthma

Surprisingly, there was no association between all socio- demography characteristics of the respondents with exacerbation of asthma frequency (Table 3).

TABLE II

SOCIO-DEMOGRAPHY CHARACTERISTICS OF RESPONDENT'S CAREGIVER $(\mathrm{N}=140)$

\begin{tabular}{|c|c|c|}
\hline Parameter & Frequency (n) & Percentage $(\%)$ \\
\hline \multicolumn{2}{|c|}{ Paternal Education Level } & \\
\hline Primer & 84 & 60.0 \\
\hline Secondary/Tertiary & 56 & 40.0 \\
\hline \multicolumn{3}{|l|}{ Paternal occupation } \\
\hline Nil/self-employed & 26 & 18.6 \\
\hline Technical & 70 & 50.0 \\
\hline Professional & 44 & 31.4 \\
\hline \multicolumn{3}{|l|}{ Family income (RM) } \\
\hline$<\mathrm{RM} 2300$ & 35 & 25.0 \\
\hline RM $2300-5599$ & 62 & 44.3 \\
\hline$\geq$ RM 5600 & 43 & 30.7 \\
\hline
\end{tabular}

RM:Ringgit Malaysia

TABLE III

ASSOCIATION OF SOCIO-DEMOGRAPHY CHARACTERISTICS OF RESPONDENTS WITH EXACERBATION OF ASTHMA

\begin{tabular}{|c|c|c|c|c|}
\hline \multirow[t]{2}{*}{ Parameter } & \multicolumn{2}{|c|}{$\begin{array}{c}\text { Mean exacerbation of } \\
\text { Asthma }\end{array}$} & \multirow[t]{2}{*}{ T-test } & \multirow[t]{2}{*}{$P$ value } \\
\hline & Mean & SD & & \\
\hline Age (years) & 10.71 & 2.65 & $-0.02 *$ & 0.79 \\
\hline \multicolumn{5}{|l|}{ Gender } \\
\hline Boys & 5.06 & 1.79 & 0.89 & 0.37 \\
\hline Girls & 4.79 & 1.77 & & \\
\hline \multicolumn{5}{|c|}{ Level of Education } \\
\hline Primary & 4.78 & 1.65 & -1.53 & 0.13 \\
\hline Secondary & 5.30 & 1.85 & & \\
\hline
\end{tabular}

$\mathrm{SD}=$ Standard deviation; T-test=Student-t test; $*=$ simple linear regression: $(\mathrm{b}$ slope $=-0.02$, constant $=5.07$ ); $p<0.05$ was considered significant

C. Association of Socio-demography Characteristics of respondents' caregivers with Exacerbation of Asthma

The same finding was observed for the association with the socio-demography characteristics of the respondents' caregivers with exacerbation of Asthma (Table 4). There was no effect of paternal level of education and occupation on the exacerbation frequency of Asthma ( $p>0.05)$. Similarly, family income did not affect the respondents frequency of Asthma exacerbation $(\mathrm{F}=1.69, \mathrm{p}=0.19)$.

\section{DISCUSSION}

140 of children aged 7 to 17 years old with Asthma were involved in this study. This study aimed to determine factors associated with exacerbation frequency among children with Asthma and specifically the factors of socioeconomic status (SES) in the family.

TABLE IV

ASSOCIATION OF SOCIO-DEMOGRAPHY CHARACTERISTICSOF RESPONDENTS' CAREGIVERS WITH EXACERBATION OF ASTHMA

\begin{tabular}{|c|c|c|c|c|}
\hline \multirow[t]{2}{*}{ Parameter } & \multicolumn{2}{|c|}{$\begin{array}{c}\text { Mean exacerbation } \\
\text { of Asthma }\end{array}$} & \multirow[t]{2}{*}{$\begin{array}{c}\text { T-test } \\
\text { F value }\end{array}$} & \multirow[t]{2}{*}{ P value } \\
\hline & Mean & SD & & \\
\hline \multicolumn{5}{|l|}{ Paternal Education Level } \\
\hline Primary & 4.78 & 1.79 & -1.53 & 0.13 \\
\hline Secondary/Tertiary & 5.30 & 1.71 & & \\
\hline \multicolumn{5}{|l|}{ Paternal occupation } \\
\hline self-employed & 4.46 & 1.63 & $1.49 *$ & 0.23 \\
\hline Technical & 5.14 & 1.78 & & \\
\hline Professional & 4.82 & 1.85 & & \\
\hline \multicolumn{5}{|l|}{ Family income (RM) } \\
\hline$<\mathrm{RM} 2300$ & 5.26 & 1.63 & $1.69 *$ & 0.19 \\
\hline RM $2300-5599$ & 4.98 & 1.81 & & \\
\hline$\geq$ RM 5600 & 4.53 & 1.82 & & \\
\hline
\end{tabular}

$\mathrm{RM}=$ Ringgit Malaysia; $\mathrm{SD}=$ Standard deviation; T-test=Student- $\mathrm{t}$ test; *F=ANOVA; $\mathrm{P}<0.05$ is considered significant

Asthma had been found to affect all social classes for various reasons, in both developed and developing countries as reported by GINA [2]. Interestingly, this study showed all the examined factors not associated with the exacerbation frequency among the children with Asthma. Our finding was supported by the reviews conducted by Rona et al [7]. The effect of SES on the asthma control among children has been observed in hospital setting [8]. However, it was less study done to relate the SES in primary health care setting. Despite, the association between the SES and asthma control have been previously characterized more towards preschool age compared older children [9]. Parent with lower age may seek early treatment for their child in primary care services. Thus, the age-varying factor on SES remains a challenge in this study.

The possibility of the parental healthcare seeking behaviour also may contribute the negative association of the study finding. There was lacking information on family choice of healthcare-related 
cost over time. Parent with higher income may seek treatment from general practitioner or private specialist care where as more inpatient care for those from the lower income group [10]. Besides, children with uncontrolled asthma also will seek treatment in the emergency department at hospital level compared to the primary health care services. There was also lack of data regarding the time of asthma exacerbation. According to the recent literature showed children will have more asthma exacerbation at night. So the possibility of the parent to get treatment for their child will be more towards the hospital compared to primary health care services [9].

The high paternal level of education had been associated with the ability to care properly, a greater appreciation of scientific knowledge, and the ability to articulate resources for the needs of the child [11]. Once the caregivers have a higher level of education, they will tend to have more knowledge about asthma and its evolution, what to do when symptoms appear, and how to prevent crises, minimizing the damage to the quality of life of the child. The low level of caregiver education was highly correlated with the socio-economic background of the family, where they have more risk of environmental exposures, access to healthcare facilities, stress, and cultural factors [12]. Our finding also indicated there was no effect of parental education level on exacerbation of asthma frequency. There are potential factors that contributing to this finding such as family life style [8], diet [10], medication compliance [6] and stress level [9]. However these factors are difficult to measure in this study. Asthma education need to be given continuously to reduce Asthma exacerbation although the finding was inconsistent with the previous study [6]. This will help to reduce the increment of healthcare cost.

Among children with Asthma involved in this study, we found that parental occupation also did not have any association on the exacerbation of Asthma. Occupational status is a complex variable and its measurement varies depending on one's theoretical perspective. Parent who classified as professional may have poor health status compared to self employed [7].
This study has limitation as it only involved primary health care setting. It also had recall bias where the parent and children with asthma need to give information of Asthma exacerbation within six month of duration. Parent who self-employed would result in underestimation of income and this may contribute to wrongly classification. These diverse of results could also be due to different study design, small sample size and varying measures of SES.

\section{$\mathrm{V}$ CONCLUSIONS}

In conclusion, our study shows that the socioeconomic factor has no relationship with asthma exacerbation. The findings added to the latest knowledge and information of asthma in Malaysia.

\section{ACKNOWLEDGMENT}

We would like to express our appreciation to the Director-General of Health Malaysia and the Universiti Kebangsaan Malaysia. We also acknowledge with gratitude the contributions of MOH PKD Melaka Tengah, research team members for their input and assisting with data collection and all patients and caregivers involved in the study.

\section{REFERENCES}

[1] To Teresa, S. Stanojevic, G. Moores et al, "Global asthma prevalence in adults: findings from the cross-sectional world health survey", BMC public health, 2012, vol. 12, pp. 204.

[2] Global Initiative for Asthma (GINA), 2013 report: Global strategy for asthma and management and prevention. Available from www.ginasthma.org.Last updated December 2012.

[3] M.B. Bahari, M. Mohd Nur, F.A.B. Rahman, "A knowledge of asthma in school children: A survey of primary school teachers." Singapore Medical Journal, 2003, vol. 44, pp. 131-135.

[4] I. Rozlan, "The study on asthma admissions in Malaysia". Disease Control Division (NCD), Ministry of Health Malaysia, 2002, vol. 1, pp. 10-17.

[5] D.J. Magid, D. Houry, J. Ellis, E. Lyons \& J.S. Rumsfeld "Health related quality of life predicts emergency department utilization for patients with asthma."Annual Emergency Medicine, 2004, vol. 43(5), pp. 551-557

[6] A. Al- Mobeireek, "Prescribing for asthmatic children in primary care. Are we following the guidelines?" Saudi Medical Journal, 2003,vol. 24, pp. 1274.

[7] R.J. Rona, "Asthma and poverty." Thorax,2000, vol.55, pp. 239 244.

[8] A.L. Kozyrskyj, G.E. Kendall, P. Jacoby, P.D. Sly, S.R. Zubrick, "Association between socioeconomic status and the development of asthma: analyses of income trajectories," American Journal of Public Health, 2010, vol. 100, pp. 540- 546.

[9] C. Almqvist, G. Pershagen, M. Wickman, "Low socioeconomic status as a risk factor for asthma, rhinitis and sensitization at 4 years in a birth cohort." Clinical and experimental allergy: journal of the British Society for Allergy and Clinical Immunology, 2006, vol. 35, pp. 612-618. 
[10] M. Halldorsson, A.E. Kunst, L. Kohler, J.P. Mackenbach, "Socioeconomic differences in children's use of physician services in the Nordic countries." Journal of Epidemiology And Community Health, 2002, vol. 56, pp. 200-204.

[11] P.L. Engle, P. Menon, L. Haddad, "Care and nutrition: concepts and measurement." Washington: International Food Policy Research Institute.1997.

[12] J.S. Halterman, H.L.Yoos, K.M. Conn, P.M Callahan, G. Montes, T.L Neely et al. "The impact of childhood asthma on parental quality of life." Journal of Asthma, 2004, vol. 41(6),pp. 645-653 